Article

\title{
Association of Circulating 25(OH)D and Lower Urinary Tract Symptoms: A Four-Year Prospective Study among Elderly Chinese Men
}

\author{
Zhao-Min Liu ${ }^{1}$, Carmen Ka Man Wong ${ }^{1}$, Dicken Chan ${ }^{1}$, Jean Woo ${ }^{2}$, Yu-Ming Chen ${ }^{3}$, \\ Bailing Chen ${ }^{4}$, Lap-Ah Tse ${ }^{5}$ and Samuel Yeung-Shan Wong ${ }^{1, *}$ \\ 1 Division of Family Medicine and Primary Care, Jockey Club School of Public Health and Primary Care, \\ the Chinese University of Hong Kong, Hong Kong 99977, China; liuzhaomin@cuhk.edu.hk (Z.-M.L.); \\ carmenwong@cuhk.edu.hk (C.K.M.W.); dicken@cuhk.edu.hk (D.C.) \\ 2 Department of Medicine and Therapeutics, the Chinese University of Hong Kong, Hong Kong 99977, China; \\ jeanwoowong@cuhk.edu.hk \\ 3 Department of Medical Statistics and Epidemiology, School of Public Health, Sun Yat-sen University, \\ Guangzhou 51000, China; chenyum@mail.sysu.edu.cn \\ 4 Department of Spine Surgery, the First Affiliated Hospital of Sun Yat-sen University, \\ Guangzhou 51000, China; chenbl2012@163.com \\ 5 Division of Occupational and Environmental Health, Jockey Club School of Public Health and Primary Care, \\ the Chinese University of Hong Kong, Hong Kong 99977, China; shelly@cuhk.edu.hk \\ * Correspondence: yeungshanwong@cuhk.edu.hk; Tel.: +852-2252-8774; Fax: +852-2606-3500
}

Received: 30 March 2016; Accepted: 4 May 2016; Published: 7 May 2016

\begin{abstract}
The role of vitamin D in relation to lower urinary tract symptoms (LUTS) remains inconclusive. This four-year longitudinal study aims to explore the association of circulating $25(\mathrm{OH}) \mathrm{D}$ and LUTS in elderly Chinese men. Two thousand Chinese men aged 65 and older were recruited from a local community, of which 1998 (99.9\%) at baseline and 1564 (78.2\%) at four-year follow-up reported data on LUTS, and 988 of the randomly chosen subpopulation were assayed for serum $25(\mathrm{OH}) \mathrm{D}$ by radioimmunoassay at baseline. LUTS were evaluated by a validated International Prostate Symptoms Scale (IPSS). Data on demographic characteristics, lifestyle factors, health, and medications were collected. Serum parathyroid and sex steroid hormones and genotypes of vitamin D receptors were assayed. The association of serum $25(\mathrm{OH}) \mathrm{D}$ and LUTS was examined by using multivariable regression models. Serum $25(\mathrm{OH}) \mathrm{D}$ was not significantly associated with the changes of IPSS or the risk of LUTS in overall participants. However, among men with $25(\mathrm{OH}) \mathrm{D} \leqslant 60 \mathrm{nmol} / \mathrm{L}$, each $10 \mathrm{nmol} / \mathrm{L}$ increase of 25(OH)D over $0 \mathrm{nmol} / \mathrm{L}$ was significantly associated with 1.3 lower points of IPSS or a $51.6 \%$ decreased risk for moderate/severe LUTS four years later. Adjustment for serum androstenedione $(p=0.019)$ and dehydropiandrosterone $(p=0.037)$ attenuated the associations. Our study suggested that among individuals with low vitamin D status, the increase of the $25(\mathrm{OH}) \mathrm{D}$ level may be associated with a lowered risk of LUTS.
\end{abstract}

Keywords: lower urinary tract symptoms; elderly men; serum $25(\mathrm{OH}) \mathrm{D}$; international prostate symptoms score

\section{Introduction}

Lower urinary tract symptoms (LUTS), a cluster of chronic urinary symptoms in the bladder, prostate or urethra, represent one of the most common clinical complaints in elderly men [1]. LUTS result from a complex interplay of pathophysiologic features, comprising a progressive, age-related combination of storage, voiding, and post-micturition symptoms [2]. Men with overactive bladder symptoms (bladder-storage dysfunction) were found to have a high prevalence of LUTS and greater 
LUTS severity. Both urological and non-urological conditions may contribute to LUTS with benign prostatic hyperplasia (BPH) being one of the principal underlying causes of LUTS [3]. A recent survey in China reported a high prevalence with $78.8 \%$ of men above 40 years of age having at least one LUTS [4]. The pervasiveness of LUTS, along with its associated medical costs, requires further understanding of the causes of LUTS and the identification of modifiable risk factors in order to prevent or delay the symptom progression.

There is increasing evidence that vitamin D deficiency or insufficiency can be an important risk factor for various adverse health outcomes [5]. However, evidence of its role in relation to LUTS is not adequately characterized. In vitro and animal studies show that vitamin D reduces cellular proliferation and differentiation of prostate acting through vitamin D receptor (VDR) [6]. VDR polymorphisms may be involved in BPH pathogenesis by encoding growth factors [7]. The circulating hormones (i.e., parathyroid and sex hormones) may influence the biological actions of vitamin $\mathrm{D}$ on prostate $[6,8]$. Cross-sectional studies also suggest a vitamin D deficiency $(25(\mathrm{OH}) \mathrm{D}$ less than $50 \mathrm{nmol} / \mathrm{L})$ or an insufficiency $(50-74.9 \mathrm{nmol} / \mathrm{L})$ or a lack of dietary vitamin D intake was associated with the increased risk of LUTS or BPH [9-11]. A cohort study by Kristal et al. reported that an increased intake of vitamin $\mathrm{D}$ from both diet and supplements or just from supplements alone may have an impact on reducing BPH prevalence [12].

Despite a dietary intake of vitamin $\mathrm{D}$, skin synthesis from sunlight exposure is the major source of vitamin D $(80 \%-90 \%)$ in humans, and the circulating $25(\mathrm{OH}) \mathrm{D}$ is the optimal indicator of overall vitamin D status [13]. To the best of our knowledge, no biomarker-based longitudinal studies have examined the relationship of serum vitamin D and the risk of LUTS and no study has explored the temporal relationship among Asian populations. Our analysis used data from a prospective study in elderly Chinese men to examine the association of serum 25(OH)D and LUTS, and we also explored the potential mechanisms on VDR gene polymorphisms and sex hormones.

\section{Materials and Methods}

\subsection{Participants}

This was a four-year longitudinal study (Mr. OS Hong Kong) among 2000 Chinese men aged 65 and older. The details of the subjects' recruitment have been described previously [14]. In brief, participants were recruited from the local community from 2001 to 2003 by placing recruitment notices in housing estates and community centers. The inclusion criteria required all participants to be able to walk or take public transport to the study site at the University's teaching hospital in Shatin. Stratified sampling was adopted to have approximately $33 \%$ of subjects in each of the following age groups: $65-69,70-74$, and $\geqslant 75$ years. Subjects were recruited on a voluntary basis, and recruitment was terminated once the target sample size was reached. Subjects were invited to the research center for interviews and physical examination. The study protocol was approved by The Chinese University of Hong Kong Ethics Committee, and informed consent was obtained from all subjects before enrollment.

\subsection{Data Collection}

Subjects were interviewed by using a set of structured and standardized questionnaires or an examination form covering the following aspects: demographic characteristics; health and medication; and lifestyle factors (such as cigarette smoking, alcohol consumption, dietary intake, and physical activity). Blood was taken after an overnight fast from all subjects. EDTA whole blood and serum samples were kept frozen at $-80^{\circ} \mathrm{C}$.

\subsubsection{Lower Urinary Tract Symptoms (LUTS)}

The presence and severity of LUTS were assessed by a validated Chinese version of the International Prostatic Symptoms Score (IPSS) [15,16]; the data for which were collected at baseline and at the end of two-year and four-year follow-ups. The IPSS is an eight-item questionnaire that includes 
seven symptom questions (i.e., nocturia, frequency, urgency, intermittency, weak stream, incomplete emptying, and straining) and one global quality-of-life question. For the seven symptom questions, each item refers to during the last month and each involves the assignment of a score from 1 to 5 for a total of 35 points. According to the IPSS, men were defined as severe LUTS if they scored $\geqslant 20$; moderate LUTS if they scored 8-19 and mild LUTS with a score $\leqslant 7$.

\subsubsection{Serum Analyses of 25(OH)D, Parathyroid Hormone (PTH), and Sex Hormones}

A subpopulation of 988 men was randomly chosen by simple random sampling and had fasting venous sampling at baseline for assay of serum $25(\mathrm{OH}) \mathrm{D}$ and PTH. Serum was stored at $-80{ }^{\circ} \mathrm{C}$, and levels of $25(\mathrm{OH}) \mathrm{D}$ were measured by a competitive radioimmunoassay (DiaSorin, Stillwater, $\mathrm{MN}, \mathrm{USA})$. This assay measures both $25(\mathrm{OH}) \mathrm{D}_{3}$ and $25(\mathrm{OH}) \mathrm{D}_{2}$. Intra- and interassay coefficients of variations (CVs) were $6 \%$ and $18 \%$, respectively. Serum intact PTH levels were measured by using an immune-luminometric assay (Diagnostic Products Corp., Los Angeles, CA, USA). The intra- and interassay CVs were $5 \%$ and $9 \%$, respectively.

A total of 1489 subjects were randomly selected by simple random sampling to have stored serum analyzed for precursors-dehydroepiandrosterone (DHEA), dehydroepiandrosterone sulfate, 5-androstene-3b,17b-diol (5-Diol), and androstenedione (4-Dione), among which 399 subjects were randomly selected for testing of sex hormone binding globulin (SHBG), testosterone, and estradiol. Free fractions of testosterone and estradiol were calculated, as described by Sodergard [17]. All hormone assays were performed by Gas chromatography-mass spectrometry (GC/MS) [18].

\subsubsection{Genotyping of VDR Tag SNPs and the Major Haplotypes}

Blood samples for DNA analyses were collected from 1680 individuals. DNA was extracted from whole blood by using standard phenol/chloroform extraction [19]. Genotypes of VDR were determined by polymerase chain reaction (PCR) amplification. The SNPs (rs731236 and rs9729) genotyped in the study cohorts and used as tag SNPs were all in Hardy-Weinberg equilibrium, and they were used for prediction of the major haplotypes in the study populations.

\subsubsection{Other Covariates}

Cigarette smoking and alcohol consumption were investigated based on self-report by using validated methods. Anthropometric measures were conducted at the baseline, two-year and four-year follow-ups by a standardized protocol. Body weight was measured with subjects wearing a light gown by the Physician Balance Beam Scale (Healthometer, Alsip, IL, USA). Height was measured by the Holtain Harpenden stadiometer (Holtain Ltd., Crosswell, UK). Body mass index (BMI) was calculated as: body weight $(\mathrm{kg}) / \mathrm{m}^{2}$. Physical activity was assessed by using the Physical Activity Scale of the Elderly (PASE) [20]. Dietary intake was assessed at baseline by using a validated semi-quantitative food frequency questionnaire (FFQ) [21].

\subsection{Statistical Analysis}

Statistical analyses were performed by using the statistical package SPSS version 19.0 (SPSS Inc., Chicago, IL, USA). A level of 5\% was used as the level of significance. Data were checked for normality, and transformation was made whenever appropriate (serum $25(\mathrm{OH}) \mathrm{D}$, and IPSS were $\log _{10}$ transformed in a linear regression model). Baseline characteristics were compared by independent $t$-test for continuous variables or by a chi-square test for categorical variables between participants with mild (IPSS < 8) and moderate/severe (IPSS $\geqslant 8$ ) LUTS, and between participants with and without testing of $25(\mathrm{OH}) \mathrm{D}$.

Multivariate linear regression models were applied to examine the associations of serum 25(OH)D level with the IPSS changes from baseline at two-year and four-year follow-ups by adjustment for potential covariates. Variables found to be associated with LUTS in univariate analyses were put into multiple regression models. Adjusted variables were age, seasons, educational level, baseline 
IPSS, cigarette smoking (no, current, ever), coffee (mL/day), alcohol (g/day), calcium supplement (yes or no), prostate medication (yes or no), BMI, history of fracture, hypertension, stroke, diabetes (yes or no), PASE total score, dietary energy (kcal/day), and isoflavones (mg/day) intakes. To avoid reverse causation, sensitivity analysis by the exclusion of subjects with severe LUTS was conducted $(n=904)$. Stratification analyses by different seasons (winter/spring $v s$. autumn/summer) and 25(OH)D levels ( $\leqslant 60$ vs. $>60 \mathrm{nmol} / \mathrm{L}$ ) were also conducted to examine whether the associations of $25(\mathrm{OH}) \mathrm{D}$ and IPSS changes were different. The cut-off of $25(\mathrm{OH}) \mathrm{D}$ level at $60 \mathrm{nmol} / \mathrm{L}$ was suggested by the General Linear Model, in which the only significant difference was observed between quintile 1 ( $\leqslant 60 \mathrm{nmol} / \mathrm{L})$ and quintile $2(60-80 \mathrm{nmol} / \mathrm{L})$. The cut-point at $60 \mathrm{nmol} / \mathrm{L}$ gave the best discrimination between those with and without an improvement in LUTS, and this was further confirmed by multivariable fractional polynomial models. We also used the conventional cut-points of $25(\mathrm{OH}) \mathrm{D}$ at 50 or $75 \mathrm{nmol} / \mathrm{L}$, which are recommended by the Institute of Medicine [22], to repeat the data analysis. However, only marginally inverse associations were observed between $25(\mathrm{OH}) \mathrm{D}$ and IPSS changes. Thus, the stratified analyses were conducted among participants with $25(\mathrm{OH}) \mathrm{D} \leqslant 60$ and $>60 \mathrm{nmol} / \mathrm{L}$.

Binary logistic regression was performed to further characterize the relationship between the serum 25(OH)D levels and the risk of moderate/severe LUTS at four-year follow-up after controlling for the above confounders. Subjects with severe LUTS (IPSS $\geqslant 20$ ) at baseline were excluded from this analysis $(n=154,7.7 \%)$. To explore the influence of season on this association, the interaction term of $25(\mathrm{OH}) \mathrm{D}$ and seasons was included in the regression model. To investigate the possible mechanisms related to VDR polymorphisms, we conducted exploratory analyses to test the interactions of genetic factors (SNPs and VDR haplotypes) and 25(OH)D with respect to IPSS by adding a cross-product term to the models, and we assessed significance with the Wald test. We also adjusted serum hormones in the regression models between 25(OH)D and absolute IPSS changes at four-year follow-up to examine whether the hormones mediated these associations.

\section{Results}

\subsection{Baseline Characteristics of Participants with Mild and Moderate/Severe LUTS}

Among the 2000 recruited elderly men, 1998 (99.9\%) at baseline, 1744 (87.2\%) at two-year and $1564(78.2 \%)$ at four-year follow-up reported data on LUTS. After excluding those with a history of bladder cancer $(n=13)$ and prostate cancer $(n=16)$, analyses were performed among 1971 elderly men at baseline. The baseline characteristics of overall participants are presented in Table 1. Compared with those with mild LUTS, the men with moderate/severe LUTS were older, less educated, more likely to be under antihypertensive treatment, had lower dietary energy, protein and calcium intakes, less alcohol and coffee drinking, lower levels of physical activity, and lower serum bioavailable estradiol levels. 
Table 1. Participants' characteristics at baseline.

\begin{tabular}{|c|c|c|c|c|}
\hline & $\begin{array}{c}\text { Overall } \\
\text { Participants }\end{array}$ & IPSS < 8 (Mild) & $\begin{array}{c}\text { IPSS } \geqslant 8 \\
\text { (Moderate/Severe) }\end{array}$ & $p$ \\
\hline$n$ & 1998 & 1178 & 820 & \\
\hline Age (year) & $72.4 \pm 5.0$ & $72.0 \pm 4.8$ & $73.0 \pm 5.2$ & 0.006 \\
\hline Body mass index (BMI, kg/m²) & $23.4 \pm 3.1$ & $23.4 \pm 3.0$ & $23.4 \pm 3.3$ & 0.99 \\
\hline Education (university or above, \%) & $271(13.6)$ & $190(16.1)$ & $81(9.9)$ & 0.001 \\
\hline Marriage (married or cohabiting, \%) & $1758(88.0)$ & $1039(88.2)$ & $719(87.7)$ & 0.73 \\
\hline Smoking (\%) & & & & 0.17 \\
\hline No smoking & $724(36.2)$ & $445(37.8)$ & $279(34.0)$ & \\
\hline Current smoking & $1036(51.9)$ & $591(50.2)$ & $445(54.3)$ & \\
\hline Passive smoking & $238(11.9)$ & $142(12.1)$ & $96(11.7)$ & \\
\hline Calcium supplement (\%) & $193(9.7)$ & $112(9.5)$ & $81(9.9)$ & 0.78 \\
\hline Multi-vitamin use (\%) & $91(4.6)$ & $60(5.1)$ & $31(3.8)$ & 0.17 \\
\hline Antihypertensive medication (\%) & $897(44.9)$ & $464(39.4)$ & $433(52.8)$ & 0.001 \\
\hline Prostate medication (\%) & $305(15.3)$ & $115(9.8)$ & $190(23.2)$ & $<0.001$ \\
\hline \multicolumn{5}{|l|}{ Medical history (\%) } \\
\hline Fracture & $274(13.7)$ & $167(14.2)$ & $107(13.0)$ & 0.47 \\
\hline Diabetes & $293(14.7)$ & $174(14.8)$ & $119(14.5)$ & 0.87 \\
\hline Stroke & $109(5.5)$ & $59(5.0)$ & $50(6.1)$ & 0.29 \\
\hline Hypertension & $835(41.8)$ & $466(39.6)$ & $369(45.0)$ & 0.02 \\
\hline Bladder cancer & $13(0.6)$ & $6(0.5)$ & $7(0.9)$ & 0.35 \\
\hline Prostate cancer & $16(0.8)$ & $6(0.5)$ & $10(1.2)$ & 0.08 \\
\hline \multicolumn{5}{|l|}{ Dietary factors } \\
\hline Energy (Kcal/day) & $2099.5 \pm 586.5$ & $2126.8 \pm 591.7$ & $2061.1 \pm 577.6$ & 0.01 \\
\hline Protein (g/day) & $87.7 \pm 35.3$ & $89.0 \pm 35.3$ & $85.7 \pm 35.2$ & 0.04 \\
\hline Fat (g/day) & $67.7 \pm 24.5$ & $68.2 \pm 24.8$ & $67.0 \pm 24.0$ & 0.28 \\
\hline Calcium (mg/day) & $628.3 \pm 297.6$ & $649.7 \pm 300.0$ & $597.6 \pm 291.8$ & $<0.001$ \\
\hline Vitamin D (IU/day) & $14.5 \pm 25.4$ & $14.7 \pm 25.2$ & $14.4 \pm 25.7$ & 0.79 \\
\hline Alcohol intake (g/day) & $25.9 \pm 113.7$ & $31.8 \pm 137.0$ & $17.4 \pm 66.4$ & 0.01 \\
\hline Coffee drinking (mL/day) & $30.5 \pm 78.0$ & $34.7 \pm 83.8$ & $24.5 \pm 68.5$ & 0.004 \\
\hline PASE total score & & $101.5 \pm 52.3$ & $91.3 \pm 46.7$ & $<0.001$ \\
\hline \multicolumn{5}{|l|}{ Major VDR haplotype groups } \\
\hline$n$ & 1606 & 948 & 658 & \\
\hline Homozygous Hap1 (\%) & $797(49.6)$ & $471(49.7 \%)$ & $326(49.5 \%)$ & 0.98 \\
\hline Homozygous Hap2 (\%) & $106(6.6)$ & $56(5.9 \%)$ & $50(7.6 \%)$ & 0.21 \\
\hline Homozygous Hap3 (\%) & $8(0.3)$ & $3(0.3 \%)$ & $5(0.3 \%)$ & 0.22 \\
\hline Heterozygous Hap1/Hap2 (\%) & $535(33.3)$ & $307(32.4 \%)$ & $228(34.7 \%)$ & 0.50 \\
\hline Heterozygous Hap1/Hap3 (\%) & $119(7.4)$ & $83(8.8 \%)$ & $36(5.5 \%)$ & 0.02 \\
\hline Heterozygous Hap2/Hap3 (\%) & 0 & 0 & 0 & - \\
\hline \multicolumn{5}{|l|}{ Serum hormones } \\
\hline$n$ & 400 & 256 & 144 & \\
\hline SHBG (nmol/L) & $42.9 \pm 16.5$ & $42.9 \pm 16.3$ & $42.9 \pm 17.1$ & 0.99 \\
\hline Bioavailable estradiol (pmol/L) & $77.7 \pm 21.3$ & $79.4 \pm 21.5$ & $74.7 \pm 20.8$ & 0.04 \\
\hline Total testerosterone $(\mathrm{nmol} / \mathrm{L})$ & $17.8 \pm 6.5$ & $18.1 \pm 6.5$ & $17.2 \pm 6.6$ & 0.18 \\
\hline Free testosterone (nmol/L) & $0.316 \pm 0.119$ & $0.323 \pm 0.121$ & $0.304 \pm 0.114$ & 0.11 \\
\hline$n^{*}$ & 1487 & 860 & 627 & \\
\hline Androstenedione (ng/mL) & $0.731 \pm 0.236$ & $0.733 \pm 0.233$ & $0.728 \pm 0.239$ & 0.65 \\
\hline Dehydroepiandrosterone sulfate (ng/mL) & $1.89 \pm 1.00$ & $1.92 \pm 0.99$ & $1.84 \pm 1.00$ & 0.13 \\
\hline 5-androstene-3b,17b-diol (ng/mL) & $0.68 \pm 0.35$ & $0.68 \pm 0.35$ & $0.67 \pm 0.36$ & 0.30 \\
\hline$n$ & 988 & 546 & 442 & \\
\hline $25(\mathrm{OH}) \mathrm{D}(\mathrm{nmol} / \mathrm{L})$ & $78.3 \pm 21.4$ & $78.5 \pm 21.1$ & $78.0 \pm 21.7$ & 0.71 \\
\hline PTH (pmol/L) & $4.49 \pm 2.38$ & $4.38 \pm 2.09$ & $4.63 \pm 2.69$ & 0.11 \\
\hline
\end{tabular}

Data were presented as mean \pm SD for continuous variables or $n(\%)$ for categorical variables. Lower Urinary Tract symptoms were evaluated by the International Prostate Symptom Score (IPSS); SHBG: Sex hormone-binding globulin. PASE: Physical Activity Scale for the Elderly; PTH: Parathyroid hormone. Body mass index (BMI) was calculated as: body weight $(\mathrm{kg}) / \mathrm{height} \cdot \mathrm{m}^{2}$. Free fractions of testosterone and estradiol were calculated, as described by Sodergard. * Two men lacked data on IPSS, and 1487 subjects were analyzed.

\subsection{Baseline Characteristics of Participants with and without 25(OH)D Testing}

Comparisons of baseline characteristics between those with and without $25(\mathrm{OH}) \mathrm{D}$ testing are presented in Table 2. There were no significant differences in educational level, smoking status, alcohol use, and dietary factors between the men with and without 25(OH)D measurement. However, the men 
with 25(OH)D measurement at baseline were older, engaged in more physical activity, had a lower BMI and higher baseline IPSS $(p<0.05)$.

Table 2. Participants' characteristics by with and without testing of serum $25(\mathrm{OH}) \mathrm{D}$ at baseline.

\begin{tabular}{lccc}
\hline & \multicolumn{2}{c}{ Testing for Serum 25(OH)D } & \multirow{2}{*}{$p$} \\
\cline { 2 - 3 } & No & Yes & \\
\hline$n$ & 1012 & 988 & \\
Age (year) & $72.0 \pm 4.9$ & $72.8 \pm 5.0$ & 0.001 \\
Body mass index (BMI, kg/m²) & $23.7 \pm 3.1$ & $23.2 \pm 3.2$ & $<0.001$ \\
Education (university or above, \%) & $134(13.2)$ & $137(13.9)$ & 0.10 \\
Marriage (married or cohabiting, \%) & $895(88.5)$ & $864(87.4)$ & 0.19 \\
Current smoking (\%) & $526(52.0)$ & $512(51.8)$ & 0.99 \\
Multi-vitamin use (\%) & $44(4.3)$ & $47(4.8)$ & 0.66 \\
Medications (\%) & & & \\
$\quad$ Prostate medication & $129(12.7)$ & $176(17.8)$ & 0.002 \\
$\quad$ Anti-androgen use & $3(0.3)$ & $4(0.4)$ & 0.68 \\
Medical history (\%) & & & \\
Fracture & $135(13.3)$ & $139(14.1)$ & 0.67 \\
$\quad$ Diabetes & $136(13.4)$ & $157(15.9)$ & 0.12 \\
Stroke & $50(4.9)$ & $59(6.0)$ & 0.31 \\
Hypertension & $426(42.1)$ & $410(41.5)$ & 0.78 \\
Heart diseases & $98(9.7)$ & $103(10.4)$ & 0.58 \\
PASE total score & $94.7 \pm 47.2$ & $99.9 \pm 53.1$ & 0.02 \\
Dietary factors & & & \\
$\quad$ Total energy (kcal/day) & $2115 \pm 603$ & $2,083 \pm 570$ & 0.22 \\
Protein (g/1000 Kcal/day) & $41.1 \pm 9.4$ & $41.3 \pm 9.5$ & 0.77 \\
Fat (g/1000 Kcal/day) & $32.3 \pm 7.3$ & $32.2 \pm 6.9$ & 0.81 \\
Alcohol intake (g/day) & $28.2 \pm 138.5$ & $23.5 \pm 80.7$ & 0.35 \\
Vitamin D (IU/day) & $14.9 \pm 29.9$ & $14.2 \pm 19.8$ & 0.56 \\
Total isoflavones (mg/day) & $16.5 \pm 26.9$ & $14.8 \pm 18.4$ & 0.11 \\
Baseline IPSS & $7.1 \pm 6.5$ & $8.5 \pm 7.2$ & $<0.001$ \\
\hline
\end{tabular}

Data were presented as mean \pm SD for continuous variables or $n(\%)$ for categorical variables. Lower Urinary Tract symptoms were evaluated by the International Prostate Symptom Score (IPSS); PASE: Physical Activity Scale for the Elderly; Body mass index (BMI) was calculated as: body weight $(\mathrm{kg}) /$ height $\mathrm{m}^{2}$.

\subsection{The Associations of Serum 25(OH)D with IPSS Changes and Risk of Moderate/Severe LUTS}

After adjustment for potential confounders, longitudinal analyses in overall participants showed that serum 25(OH)D level in continuous form was not significantly associated with the IPSS changes from baseline (Table 3), or with the risk of moderate/severe LUTS (Table 4) at two-year and four-year follow-ups in both the crude or adjusted models. Sensitivity analysis by the exclusion of participants with severe LUTS and stratified analysis by seasons indicated similar non-significant results with those of overall participants.

However, subgroup analysis among the men with $25(\mathrm{OH}) \mathrm{D}$ level $\leqslant 60 \mathrm{nmol} / \mathrm{L}$ indicated that there was a significant association of serum $25(\mathrm{OH}) \mathrm{D}$ and decreased scores of LUTS (unadjusted coefficient $\mathrm{B}=-0.155, p=0.02)$, or a reduced risk of moderate/severe LUTS with a risk ratio of 0.930 (95\% CI: $0.872,0.992, p=0.02$ ) at four-year follow-up after adjusting for covariates (Tables 3 and 4 ). Analysis among the subclasses of LUTS suggested that the major improvement in LUTS could be occurring in urinary intermittency, frequency, and urgency (Table 3). There was no significant interaction between $25(\mathrm{OH}) \mathrm{D}$ and seasons $(p=0.172)$. In addition, no significant association (either linear or non-linear) was detected among those with a 25(OH)D level $>60 \mathrm{nmol} / \mathrm{L}$. 
Table 3. Univariate and multivariate linear regression analyses on the association of serum $25(\mathrm{OH}) \mathrm{D}$ and the changes of International Prostate Symptom Score (IPPS) at two-year and four-year follow-ups as well as stratified analyses by different $25(\mathrm{OH}) \mathrm{D}$ levels, seasons and severity of LUTS.

\begin{tabular}{|c|c|c|c|c|}
\hline & \multicolumn{2}{|c|}{ Crude } & \multicolumn{2}{|c|}{ Adjusted } \\
\hline & $\beta$ & $p$ & $\beta$ & $p$ \\
\hline \multicolumn{5}{|l|}{ All participants $(n=967)$} \\
\hline IPSS change at 2-year FU & -0.002 & 0.93 & -0.007 & 0.73 \\
\hline IPSS change at 4 -year FU & -0.012 & 0.61 & -0.005 & 0.80 \\
\hline \multicolumn{5}{|c|}{ Stratified analysis by serum $25(\mathrm{OH}) \mathrm{D}$ level $(>$ or $\leqslant 60 \mathrm{nmol} / \mathrm{L})$} \\
\hline \multicolumn{5}{|c|}{$25(\mathrm{OH}) \mathrm{D}>60 \mathrm{nmol} / \mathrm{L}(n=771)$} \\
\hline IPSS change at 2-year FU & -0.016 & 0.66 & -0.006 & 0.86 \\
\hline IPSS change at 4-year FU & -0.046 & 0.20 & -0.040 & 0.23 \\
\hline \multicolumn{5}{|l|}{$25(\mathrm{OH}) \mathrm{D} \leqslant 60 \mathrm{nmol} / \mathrm{L}(n=196)$} \\
\hline IPSS change at 2-year FU & -0.056 & 0.44 & -0.596 & 0.55 \\
\hline IPSS change at 4-year FU & -0.155 & 0.02 & -0.149 & 0.03 \\
\hline \multicolumn{5}{|c|}{ IPSS change in individual symptoms at 4-year FU } \\
\hline Intermittency & -0.174 & 0.02 & -0.145 & 0.05 \\
\hline Frequency & -0.121 & 0.09 & -0.121 & 0.10 \\
\hline Incomplete emptying & -0.016 & 0.83 & -0.023 & 0.75 \\
\hline Urgency & -0.128 & 0.07 & -0.125 & 0.08 \\
\hline Slow/weak stream & -0.004 & 0.96 & 0.010 & 0.89 \\
\hline Straining to void & -0.002 & 0.98 & -0.026 & 0.72 \\
\hline Nocturia & -0.081 & 0.26 & -0.096 & 0.19 \\
\hline Quality of life & 0.020 & 0.78 & 0.027 & 0.73 \\
\hline \multicolumn{5}{|l|}{ Stratified analysis by seasons } \\
\hline \multicolumn{5}{|c|}{$25(\mathrm{OH}) \mathrm{D}$ assessed in winter or spring $(n=466)$} \\
\hline IPSS change at 2-year FU & 0.001 & 0.99 & 0.001 & 0.99 \\
\hline IPSS change at 4-year FU & 0.094 & 0.37 & 0.037 & 0.72 \\
\hline \multicolumn{5}{|c|}{$25(\mathrm{OH})$ D assessed in summer or autumn $(n=501)$} \\
\hline IPSS change at 2-year FU & 0.023 & 0.76 & 0.011 & 0.88 \\
\hline IPSS change at 4-year FU & -0.015 & 0.85 & -0.024 & 0.75 \\
\hline \multicolumn{5}{|c|}{ Sensitivity analysis with exclusion of participants with severe LUTS $(n=904)$} \\
\hline IPSS change at 2-year FU & 0.006 & 0.93 & -0.017 & 0.79 \\
\hline IPSS change at 4-year FU & -0.029 & 0.64 & -0.031 & 0.62 \\
\hline
\end{tabular}

Data analyses were conducted by univariate and multivariate linear regression models with IPSS changes as continuous variable; $\beta$ : standardized B coefficient. The adjusted variables included age, season, educational level, baseline Prostate Symptom Score, cigarette smoking (no, current, ever), coffee(mL/day), alcohol (g/day), calcium supplement (yes or no), prostate medication (yes or no), body mass index (BMI), history of fracture, hypertension, stroke or diabetes (yes or no), PASE total score, dietary energy ( $\mathrm{kcal} /$ day) and dietary isoflavones (mg/day) intake, etc. IPSS: International Prostate Symptoms Score; FU: follow-up; $\beta$ : standardized B coefficient; PASE: Physical Activity Scale for the Elderly.

Table 4. Risk ratio (RR) and 95\% CI confidence interval for moderate/severe Lower Urinary Tract Symptoms (LUTS) at two-year and four-year follow-ups according to the baseline serum 25(OH)D levels.

\begin{tabular}{cccccc}
\hline & No. & Univariate RR (95\% CI) & $p$ & Multivariate RR (95\% CI) & $p$ \\
\hline All participants & & & & & \\
2-year FU & 871 & $0.998(0.991,1.004)$ & 0.53 & $0.997(0.990,1.004)$ & 0.37 \\
4-year FU & 683 & $1.001(0.994,1.008)$ & 0.79 & $1.000(0.992,1.008)$ & 0.98 \\
Participants with & $25(\mathrm{OH}) \mathrm{D} \leqslant 60 \mathrm{nmol} / \mathrm{L}$ & & & \\
2-year FU & 176 & $0.975(0.931,1.021)$ & 0.27 & $0.960(0.911,1.012)$ & 0.13 \\
4-year FU & 139 & $0.937(0.888,0.990)$ & 0.02 & $0.930(0.872,0.992)$ & 0.02 \\
\hline
\end{tabular}

Data were analyzed by binary logistic regression models with exclusion of men with severe lower urinary tract symptoms (PSS $\geqslant 20$ ); RR: risk ratio; 95\% CI: 95\% confidence interval; FU: follow up; The adjusted variables include age, season, educational level, baseline Prostate Symptom Score, cigarette smoking (no, current, ever), coffee(mL/day), alcohol (g/day), calcium supplement (yes or no), prostate medication (yes or no), body mass index (BMI), history of fracture, hypertension, stroke, diabetes (yes or no), PASE total score, dietary energy ( $\mathrm{kcal} /$ day), vitamin D (IU/day) and isoflavones (mg/day) intake etc. LUTS: Lower Urinary Tract Symptoms; PASE: Physical Activity Scale for the Elderly. 
Among men with $25(\mathrm{OH}) \mathrm{D} \leqslant 60 \mathrm{nmol} / \mathrm{L}$, there were no significant interactions between their serum 25(OH)D level and their genetic factors of VDR (SNPs and VDR haplotypes) that influenced the risk of moderate/severe LUTS. The $p$ values for the interactions were $0.580,0.525,0.580,0.859$, and 0.947 for DNArs9729, DNArs731236, Hap1, Hap2, and Hap3, respectively. Adjustment for serum adrostenedione $(p=0.019)$ and dehydropiandrosterone $(p=0.037)$ levels significantly attenuated the association of 25(OH)D and the four-year change of IPSS in the univariate regression models (Table S1).

\section{Discussion}

To the best of our knowledge, this is the first prospective study that examined the temporal association of serum vitamin D and LUTS in community-dwelling elderly Chinese men. In this four-year cohort study, serum 25(OH)D was not significantly associated with the severity of LUTS in overall participants. However, a significant association between the increase of $25(\mathrm{OH}) \mathrm{D}$ and the decreased risk of LUTS was observed among men with a low $25(\mathrm{OH}) \mathrm{D}$ status $(\leqslant 60 \mathrm{nmol} / \mathrm{L})$. For individuals with $25(\mathrm{OH}) \mathrm{D} \leqslant 60 \mathrm{nmol} / \mathrm{L}$, each $10 \mathrm{nmol} / \mathrm{L}$ increase of $25(\mathrm{OH}) \mathrm{D}$ over $0 \mathrm{nmol} / \mathrm{L}$ was significantly associated with 1.3 lower points of IPSS or a $51.6 \%$ decreased risk for moderate or severe LUTS. Although the effect size was modest relative to the medication treatment [23], it may still have important public health implications for the improvement of LUTS in consideration of the high prevalence of LUTS or BPH in elderly men, especially if a possible intervention offers high compliance through a well-tolerated, inexpensive, and safe supplement such as vitamin D.

\subsection{Results Explanation}

Our findings among elderly men with low vitamin D status are consistent with previous cross-sectional studies in men $[9,10]$ and women [24], which show that low serum vitamin D was associated with an increased odds of LUTS. The cross-sectional data among US adults [9] reported that vitamin D deficiency $(25(\mathrm{OH}) \mathrm{D}<50 \mathrm{nmol} / \mathrm{L})$ was associated with the presence of moderate-severe urinary incontinence (OR 1.8, 95\% CI: 1.1-3.0) and at least one LUTS (OR 1.4, 95\% CI: 1.0-2.0). Kristal et al. [12] investigated the dietary factors and the seven-year incidence of symptomatic BPH among men aged 54-86, and they reported that the highest quintile of total vitamin D intake was associated with an $18 \%$ reduced risk of BPH than the lowest one. However, total vitamin D (diet plus supplement) intake in this study was self-reported and circulating vitamin D status was unknown. A randomized controlled trial [25] suggested a promising result with vitamin D supplementation on $\mathrm{BPH}$. The study indicated that vitamin D analogue decreased $2.9 \%$ prostate volume in $\mathrm{BPH}$ patients; however, no significant changes were found in scores of urological symptoms. Thus, further interventional studies among men with low vitamin D status are needed to clarify the effect of vitamin D on LUTS or BPH.

In this four-year longitudinal study, no significant association was observed between the serum $25(\mathrm{OH}) \mathrm{D}$ level and the changes of IPSS or the risk of LUTS in the overall population. The lack of association may be due to the relatively short duration (four years), or the relatively adequate vitamin D levels in our study. However, prospective studies [26-28] with shorter duration than ours still observed significant associations of lifestyle factors with the progression of LUTS. Although the typical diet in the Chinese population is limited in vitamin-D-rich or fortified foods, the higher functional status of the participants and also their likely greater sun exposure from outdoor activities than in the general population of a similar age may account for the relatively higher vitamin $D$ status in our study [29]. Vitamin D deficiency may also suggest an overall frail condition represented by a low vitamin D level; however, the adjustment for multiple comorbid factors (diabetes, hypertension stroke, hypertension, cancers, etc.) did not change the significance of the findings.

Previous observations suggested that there are significant associations between serum $25(\mathrm{OH}) \mathrm{D}$ and health parameters, and these were mostly reported in populations with lower vitamin D status [30-32]. The thresholds of 25(OH)D levels have varied with different health outcomes, settings, study designs, and the analytical methods used to measure 25(OH)D [33]. A study in the Netherlands 
reported that the threshold of about $40 \mathrm{nmol} / \mathrm{L}$ existed for bone turnover markers, $50 \mathrm{nmol} / \mathrm{L}$ for bone mineral density, and $60 \mathrm{nmol} / \mathrm{L}$ for physical performance [34]. Another case-control study [35] showed a significant non-linear relationship that $25(\mathrm{OH}) \mathrm{D}$ was inversely associated with hip fracture only below $70 \mathrm{nmol} / \mathrm{L}$. Different thresholds of 25(OH)D insufficiency for various health outcomes may be explained by the extra-renal hydroxylation of $25(\mathrm{OH}) \mathrm{D}$ to the active metabolite $1,25(\mathrm{OH})_{2} \mathrm{D}$ in different organs because $1,25(\mathrm{OH})_{2} \mathrm{D}$ is capable of acting via autocrine and paracrine mechanisms [33]. Our results suggested that the threshold of $25(\mathrm{OH}) \mathrm{D}$ corresponding to improved LUTS might be at $60 \mathrm{nmol} / \mathrm{L}$. However, the findings were derived from a small subpopulation $(n=196)$ and based on exploratory analysis in nature; therefore, future large prospective studies are necessary to confirm the threshold of $25(\mathrm{OH}) \mathrm{D}$ on the improvement of prostate symptoms.

Our longitudinal data reported an inverse association between $25(\mathrm{OH}) \mathrm{D}$ and the decreased risk of LUTS among those with low $25(\mathrm{OH}) \mathrm{D}$ status. This association may not be related to VDR gene polymorphisms, but it may be mediated by serum adrostenedione or dehydropiandrosterone levels. In vitro and animal studies have indicated that vitamin $\mathrm{D}$ can regulate the gene expression and enzyme activity of a number of steroidogenic enzymes, and decrease the production of corticosterone, androstenedione, and dehydroepiandrosterone [36], which could thus moderate the hormonally regulated prostate growth and smooth muscle tone that cause BPH and LUTS [37]. Our findings are consistent with preclinical trials that vitamin $\mathrm{D}$ could decrease prostate cell proliferation and that the effect was induced by sex hormones or growth-promoting molecules [8].

Studies of animal models and human cell lines have shown low vitamin D status could promote cell proliferation and decrease apoptosis in normal prostate cells [38]. In addition, VDR agonist could not only inhibit prostate growth and inflammation [39], but also modulate bladder contractile mechanisms [40] and thereby prevent bladder outlet obstruction [41] in vitro and in vivo, which provides plausible mechanisms on vitamin D and a reduced risk of LUTS. VDR are known to exist in prostate and bladder tissues and the prostate has been recognized as an extra-renal site for the synthesis of $1,25(\mathrm{OH})_{2} \mathrm{D}_{3}$. Evidence suggests that VDR polymorphisms are important in modifying the receptor function [42]. However, our findings are in line with recent meta-analysis that VDR gene polymorphisms are not associated with the risk of BPH either for Caucasians or Asians [43].

\subsection{Strengths}

There are several strengths to our study. Firstly, we employed a prospective design and included a large number of potential confounding factors. Secondly, we tested the serum 25(OH)D level which best reflects overall vitamin $\mathrm{D}$ status, thus providing the most direct evidence on the association of vitamin D and LUTS. Thirdly, the possibility of reverse causality appears unlikely because the association of vitamin D and LUTS or prostate health is not extensively acknowledged and there is little concern that men with moderate or severe LUTS will seek vitamin D supplementation. In addition, sensitivity analysis with the exclusion of participants with severe LUTS reported similar findings with overall participants.

\subsection{Limitations}

Our study has several limitations. Firstly, serum 25(OH)D data were available only in half of the male subjects. In addition, $25(\mathrm{OH}) \mathrm{D}$ levels were measured at a single point of time and this may not adequately reflect long-term vitamin D status. Nevertheless, previous reports suggested a strong correlation between $25(\mathrm{OH}) \mathrm{D}$ values measured at three years $(r=0.7)$ [44] and 11 years $(r=0.5)[45]$ apart.

Secondly, the significant inverse association of $25(\mathrm{OH}) \mathrm{D}$ and IPSS change among men with low vitamin D levels was derived from a small subgroup analysis, and therefore the findings should be treated with caution. Further prospective studies with larger numbers of participants or studies specifically designed among men with low vitamin D status are needed to confirm this finding. 
Thirdly, LUTS in our study was evaluated by using a validated scale. The IPSS has many advantages because it is self-administered, sensitive to changes, and generalizable to different populations and socio-economic groups. However, the IPSS does not address urinary incontinence. It may underestimate LUTS severity in men with storage symptoms. Additionally, an assessment of surgical BPH or diagnosed BPH was not conducted. However, $\mathrm{BPH}$ is a significant contributor to LUTS in men. The diagnostic instruments for BPH would be more time-consuming and invasive and impractical in a large cohort like ours. Moreover, LUTS have been shown to exhibit progression and regression over time. Thus, the one-month recall timeframe of the IPSS questions may confound our results. However, the exclusion of severe LUTS at baseline and the measurement of IPSS changes over time could reduce the impact of these fluctuations in our study.

Finally, the study sample consisted of volunteers who were all of a higher educational level and more likely to be married compared with the general Hong Kong population in the same sex and age groups [46], and therefore the results may not be entirely generalizable. However, the selection bias would not affect the estimates of the exposure-outcome associations [47].

\section{Conclusions}

This four-year cohort study among elderly Chinese men indicated that, although the serum 25(OH)D level was not associated with LUTS in the overall population, among those with a low vitamin $\mathrm{D}(\leqslant 60 \mathrm{nmol} / \mathrm{L})$ status, $25(\mathrm{OH}) \mathrm{D}$ may be associated with a lowered risk of LUTS. Further prospective studies specifically conducted among elderly men with low vitamin D status are warranted to confirm this finding.

Supplementary Materials: The following are available online at http:/ www.mdpi.com/2072-6643/8/5/273/s1 . Table S1: Results of univariate analysis between serum $25(\mathrm{OH}) \mathrm{D}$ level and International Prostate Symptoms Score (IPSS) change at four-year follow-up by adjusting serum hormone levels in elderly men with baseline $25(\mathrm{OH}) \mathrm{D} \leqslant 60 \mathrm{nmol} / \mathrm{L}(n=196)$.

Acknowledgments: The study was supported by the National Institutes of Health R01 grant AR049439-01A1 and the Research Grants Council of Hong Kong Earmarked Grant CUHK4101/02 M. We wish to thank all participants for their participation and Edith Lau for her contribution in setting up the cohort.

Author Contributions: Z.-M.L. and S.Y.-S.W. conceptualized the study. Z.-M.L. analyzed the data and drafted the manuscript. D.C. provided help in the statistical consultation. Z.-M.L., C.W., D.C., J.W., Y.-M.C., B.C., L.A.T. and S.Y.-S.W. critically commented upon and revised the manuscript.

Conflicts of Interest: The authors declare that none of them have any conflict of interest. The funding sponsor had no role in the study design, data collection, analyses, or interpretation of the data, and none in the manuscript writing and publication.

\section{Abbreviations}

The following abbreviations are used in this manuscript:

$\begin{array}{ll}\text { LUTS } & \text { lower urinary tract symptoms } \\ \text { IPSS } & \text { International Prostate Symptoms Scale } \\ \text { VDR } & \text { vitamin D receptor } \\ \text { BPH } & \text { benign prostatic hyperplasia } \\ \text { CV } & \text { coefficients of variation } \\ \text { DHEA } & \text { dehydroepiandrosterone } \\ \text { SHBG } & \text { sex hormone binding globulin } \\ \text { BMI } & \text { body mass index } \\ \text { PASE } & \text { Physical Activity Scale of the Elderly } \\ \text { FFQ } & \text { food frequency questionnaire } \\ \text { GLM } & \text { General Linear Model }\end{array}$




\section{References}

1. Cornu, J.N.; Lukacs, B. Lower urinary tract symptoms in men: Refocus on your patients. Eur. Urol. 2015, 67, 1110-1111. [CrossRef] [PubMed]

2. Chapple, C.R. Lower urinary tract symptoms revisited. Eur. Urol. 2009, 56, 21-23. [CrossRef] [PubMed]

3. Warren, K.; Burden, H.; Abrams, P. Lower urinary tract symptom: Still too much focus on the prostate? Curr. Opin. Urol. 2014, 24, 3-9. [CrossRef] [PubMed]

4. Wang, Y.; Hu, H.; Xu, K.; Wang, X.; Na, Y.; Kang, X. Prevalence, risk factors and the bother of lower urinary tract symptoms in china: A population-based survey. Int. Urogynecol. J. 2015, 26, 911-919. [CrossRef] [PubMed]

5. Holick, M.F. Vitamin d deficiency. N. Engl. J. Med. 2007, 357, 266-281. [CrossRef] [PubMed]

6. Swami, S.; Krishnan, A.V.; Feldman, D. Vitamin d metabolism and action in the prostate: Implications for health and disease. Mol. Cell. Endocrinol. 2011, 347, 61-69. [CrossRef] [PubMed]

7. Mullan, R.J.; Bergstralh, E.J.; Farmer, S.A.; Jacobson, D.J.; Hebbring, S.J.; Cunningham, J.M.; Thibodeau, S.N.; Lieber, M.M.; Jacobsen, S.J.; Roberts, R.O. Growth factor, cytokine, and vitamin d receptor polymorphisms and risk of benign prostatic hyperplasia in a community-based cohort of men. Urology 2006, 67, 300-305. [CrossRef] [PubMed]

8. Espinosa, G.; Esposito, R.; Kazzazi, A.; Djavan, B. Vitamin d and benign prostatic hyperplasia-A review. Can. J. Urol. 2013, 20, 6820-6825. [PubMed]

9. Vaughan, C.P.; Johnson, T.M., 2nd; Goode, P.S.; Redden, D.T.; Burgio, K.L.; Markland, A.D. Vitamin d and lower urinary tract symptoms among us men: Results from the 2005 to 2006 national health and nutrition examination survey. Urology 2011, 78, 1292-1297. [CrossRef] [PubMed]

10. Parker-Autry, C.Y.; Markland, A.D.; Ballard, A.C.; Downs-Gunn, D.; Richter, H.E. Vitamin d status in women with pelvic floor disorder symptoms. Int. Urogynecol. J. 2012, 23, 1699-1705. [CrossRef] [PubMed]

11. Haghsheno, M.A.; Mellstrom, D.; Behre, C.J.; Damber, J.E.; Johansson, H.; Karlsson, M.; Lorentzon, M.; Peeker, R.; Barret-Connor, E.; Waern, E.; et al. Low 25-oh vitamin d is associated with benign prostatic hyperplasia. J. Urol. 2013, 190, 608-614. [CrossRef] [PubMed]

12. Kristal, A.R.; Arnold, K.B.; Schenk, J.M.; Neuhouser, M.L.; Goodman, P.; Penson, D.F.; Thompson, I.M. Dietary patterns, supplement use, and the risk of symptomatic benign prostatic hyperplasia: Results from the prostate cancer prevention trial. Am. J. Epidemiol. 2008, 167, 925-934. [CrossRef] [PubMed]

13. Calvo, M.S.; Whiting, S.J.; Barton, C.N. Vitamin d fortification in the united states and canada: Current status and data needs. Am. J. Clin. Nutr. 2004, 80, 1710S-1716S. [PubMed]

14. Wong, S.Y.; Leung, J.C.; Woo, J. A prospective study on the association between lower urinary tract symptoms (luts) and erectile dysfunction: Results from a large study in elderly chinese in southern china. J. Sex. Med. 2009, 6, 2024-2031. [CrossRef] [PubMed]

15. Shiri, R.; Hakkinen, J.; Koskimaki, J.; Hakama, M.; Tammela, T.L.; Auvinen, A. Erectile dysfunction influences the subsequent incidence of lower urinary tract symptoms and bother. Int. J. Impot. Res. 2007, 19, 317-320. [CrossRef] [PubMed]

16. Choi, E.P.; Lam, C.L.; Chin, W.Y. Validation of the international prostate symptom score in chinese males and females with lower urinary tract symptoms. Health Qual. Life Outcomes 2014, 12, 1. [CrossRef] [PubMed]

17. Södergard, R.; Bäckström, T.; Shanbhag, V.; Carstensen, H. Calculation of free and bound fractions of testosterone and estradiol-17 $\beta$ to human plasma proteins at body temperature. J. Steroid Biochem. 1982, 16, 801-810. [CrossRef]

18. Labrie, F.; Cusan, L.; Gomez, J.L.; Martel, C.; Berube, R.; Belanger, P.; Belanger, A.; Vandenput, L.; Mellstrom, D.; Ohlsson, C. Comparable amounts of sex steroids are made outside the gonads in men and women: Strong lesson for hormone therapy of prostate and breast cancer. J. Steroid Biochem. Mol. Biol. 2009, 113, 52-56. [CrossRef] [PubMed]

19. Mitra, S.; Desai, M.; Ikram Khatkhatay, M. Vitamin d receptor gene polymorphisms and bone mineral density in postmenopausal indian women. Maturitas 2006, 55, 27-35. [CrossRef] [PubMed]

20. Washburn, R.A.; Smith, K.W.; Jette, A.M.; Janney, C.A. The physical activity scale for the elderly (pase): Development and evaluation. J. Clin. Epidemiol. 1993, 46, 153-162. [CrossRef] 
21. Woo, J.; Leung, S.S.F.; Ho, S.C.; Lam, T.H.; Janus, E.D. A food frequency questionnaire for use in the Chinese population in Hong Kong: Description and examination of validity. Nutr. Res. 1997, 17, 1633-1641. [CrossRef]

22. Holick, M.F. Vitamin d status: Measurement, interpretation, and clinical application. Ann. Epidemiol. 2009, 19, 73-78. [CrossRef] [PubMed]

23. Barry, M.J.; Williford, W.O.; Chang, Y.; Machi, M.; Jones, K.M.; Walker-Corkery, E.; Lepor, H. Benign prostatic hyperplasia specific health status measures in clinical research: How much change in the american urological association symptom index and the benign prostatic hyperplasia impact index is perceptible to patients? J. Urol. 1995, 154, 1770-1774. [CrossRef]

24. Foti, D.; Greco, M.; Cantiello, F.; Damiano, R.; Gulletta, E.; Pujia, A.; Montalcini, T. Hypovitaminosis d and low urinary tract symptoms in a female population. Eur. J. Inflamm. 2014, 12, 365-372.

25. Colli, E.; Rigatti, P.; Montorsi, F.; Artibani, W.; Petta, S.; Mondaini, N.; Scarpa, R.; Usai, P.; Olivieri, L.; Maggi, M. Bxl628, a novel vitamin d3 analog arrests prostate growth in patients with benign prostatic hyperplasia: A randomized clinical trial. Eur. Urol. 2006, 49, 82-86. [CrossRef] [PubMed]

26. Nyunt, M.S.; Fones, C.; Niti, M.; Ng, T.P. Criterion-based validity and reliability of the geriatric depression screening scale (gds-15) in a large validation sample of community-living asian older adults. Aging Ment. Health 2009, 13, 376-382. [CrossRef] [PubMed]

27. Parsons, J.K. Lifestyle factors, benign prostatic hyperplasia, and lower urinary tract symptoms. Curr. Opin. Urol. 2011, 21, 1-4. [CrossRef] [PubMed]

28. Dallosso, H.; Matthews, R.; McGrother, C.; Donaldson, M. Diet as a risk factor for the development of stress urinary incontinence: A longitudinal study in women. Eur. J. Clin. Nutr. 2004, 58, 920-926. [CrossRef] [PubMed]

29. Chan, R.; Chan, C.C.; Woo, J.; Ohlsson, C.; Mellstrom, D.; Kwok, T.; Leung, P.C. Serum 25-hydroxyvitamin d, bone mineral density, and non-vertebral fracture risk in community-dwelling older men: Results from $\mathrm{Mr}$. Os, Hong Kong. Arch. Osteoporos. 2011, 6, 21-30. [CrossRef] [PubMed]

30. Annweiler, C.; Schott, A.M.; Allali, G.; Bridenbaugh, S.A.; Kressig, R.W.; Allain, P.; Herrmann, F.R.; Beauchet, $\mathrm{O}$. Association of vitamin d deficiency with cognitive impairment in older women: Cross-sectional study. Neurology 2010, 74, 27-32. [CrossRef] [PubMed]

31. May, H.T.; Bair, T.L.; Lappe, D.L.; Anderson, J.L.; Horne, B.D.; Carlquist, J.F.; Muhlestein, J.B. Association of vitamin d levels with incident depression among a general cardiovascular population. Am. Heart J. 2010, 159, 1037-1043. [CrossRef] [PubMed]

32. Hoogendijk, W.J.; Lips, P.; Dik, M.G.; Deeg, D.J.; Beekman, A.T.; Penninx, B.W. Depression is associated with decreased 25-hydroxyvitamin d and increased parathyroid hormone levels in older adults. Arch. Gen. Psychiatry 2008, 65, 508-512. [CrossRef] [PubMed]

33. Souberbielle, J.C.; Friedlander, G.; Kahan, A.; Cormier, C. Evaluating vitamin d status. Implications for preventing and managing osteoporosis and other chronic diseases. Jt. Bone Spine 2006, 73, 249-253. [CrossRef] [PubMed]

34. Kuchuk, N.O.; Pluijm, S.M.; van Schoor, N.M.; Looman, C.W.; Smit, J.H.; Lips, P. Relationships of serum 25-hydroxyvitamin $\mathrm{d}$ to bone mineral density and serum parathyroid hormone and markers of bone turnover in older persons. J. Clin. Endocrinol. Metab. 2009, 94, 1244-1250. [CrossRef] [PubMed]

35. De Koning, L.; Henne, D.; Hemmelgarn, B.R.; Woods, P.; Naugler, C. Non-linear relationship between serum 25-hydroxyvitamin d concentration and subsequent hip fracture. Osteoporos. Int. 2013, 24, 2061-2065. [CrossRef] [PubMed]

36. Miller, W.L. Steroid hormone synthesis in mitochondria. Mol. Cell. Endocrinol. 2013, 379, 62-73. [CrossRef] [PubMed]

37. Ho, C.K.; Habib, F.K. Estrogen and androgen signaling in the pathogenesis of bph. Nat. Rev. Urol. 2011, 8, 29-41. [CrossRef] [PubMed]

38. Barreto, A.M.; Schwartz, G.G.; Woodruff, R.; Cramer, S.D. 25-hydroxyvitamin d3, the prohormone of 1,25-dihydroxyvitamin $\mathrm{d} 3$, inhibits the proliferation of primary prostatic epithelial cells. Cancer Epidemiol. Biomark. Prev. 2000, 9, 265-270.

39. Manchanda, P.K.; Kibler, A.J.; Zhang, M.; Ravi, J.; Bid, H.K. Vitamin d receptor as a therapeutic target for benign prostatic hyperplasia. Indian J. Urol. 2012, 28, 377-381. [PubMed] 
40. Morelli, A.; Squecco, R.; Failli, P.; Filippi, S.; Vignozzi, L.; Chavalmane, A.K.; Fibbi, B.; Mancina, R.; Luciani, G.; Gacci, M.; et al. The vitamin d receptor agonist elocalcitol upregulates l-type calcium channel activity in human and rat bladder. Am. J. Physiol. Cell Physiol. 2008, 294, C1206-C1214. [CrossRef] [PubMed]

41. Schroder, A.; Colli, E.; Maggi, M.; Andersson, K.E. Effects of a vitamin d(3) analogue in a rat model of bladder outlet obstruction. BJU Int. 2006, 98, 637-642. [CrossRef] [PubMed]

42. Adorini, L.; Penna, G.; Amuchastegui, S.; Cossetti, C.; Aquilano, F.; Mariani, R.; Fibbi, B.; Morelli, A.; Uskokovic, M.; Colli, E.; et al. Inhibition of prostate growth and inflammation by the vitamin d receptor agonist bxl-628 (elocalcitol). J. Steroid Biochem. Mol. Biol. 2007, 103, 689-693. [CrossRef] [PubMed]

43. Zeng, X.T.; Yao, Q.S.; Weng, H.; Li, S.; Huang, J.Y.; Wang, X.H. Meta-analysis of vitamin d receptor gene polymorphisms and benign prostatic hyperplasia risk. Mol. Biol. Rep. 2014, 41, 6713-6717. [CrossRef] [PubMed]

44. Platz, E.A.; Leitzmann, M.F.; Hollis, B.W.; Willett, W.C.; Giovannucci, E. Plasma 1,25-dihydroxy- and 25-hydroxyvitamin $d$ and subsequent risk of prostate cancer. Cancer Causes Control 2004, 15, 255-265. [CrossRef] [PubMed]

45. Melhus, H.; Snellman, G.; Gedeborg, R.; Byberg, L.; Berglund, L.; Mallmin, H.; Hellman, P.; Blomhoff, R.; Hagstrom, E.; Arnlov, J.; et al. Plasma 25-hydroxyvitamin d levels and fracture risk in a community-based cohort of elderly men in sweden. J. Clin. Endocrinol. Metab. 2010, 95, 2637-2645. [CrossRef] [PubMed]

46. Wong, S.Y.; Woo, J.; Leung, J.C.; Leung, P.C. Depressive symptoms and lifestyle factors as risk factors of lower urinary tract symptoms in southern chinese men: A prospective study. Aging Male 2010, 13, 113-119. [CrossRef] [PubMed]

47. Mealing, N.M.; Banks, E.; Jorm, L.R.; Steel, D.G.; Clements, M.S.; Rogers, K.D. Investigation of relative risk estimates from studies of the same population with contrasting response rates and designs. BMC Med. Res. Methodol. 2010, 10, 26. [CrossRef] [PubMed]

(C) 2016 by the authors; licensee MDPI, Basel, Switzerland. This article is an open access article distributed under the terms and conditions of the Creative Commons Attribution (CC-BY) license (http://creativecommons.org/licenses/by/4.0/). 